optic nerve-fibres, to sclerosis in patches, or to travelling degenerations, rather than to meningitis. Very commonly it is due to what, for brevity's sake, we may call Wallerism, from the well-known experiments of Waller upon the travelling degenerations of nervous fibres. Now, as I have said, atrophy of the dises is seen, not in injuries of the spine, but in slow degeneration of the cord-in cases, that is, where meningitis is usually absent or inactive; and it is seen most frequently by far in that degeneration of the cord called sclerosis of the posterior columns.

Supposing, therefore, that atrophy of the disc in encephalic disease is due generally to travelling degeneration, this supposition, in the case of spinal optic atrophy also, is supported by the remarkable fact that it occurs especially with degeneration of that part of the cord-the posterior columns - which tends to travel towards the encephalon, and not towards the periphery. Thus we are led to conjecture that the optic atrophy is, in some obscure way, the result of the propagation of the destructive change upwards; and that in all cases of degeneration of the cord accompanied by atrophy of the optic nerves the degeneration includes the posterior columns, and climbs upward by means of these. Can we get any farther? Perhaps we may venture upon another step in the dark. If wasting of the posterior columns creeps upwards, it creeps up to the cerebellum. Now we know that diseases of the cerebellum are very commonly associated with atrophy of the optic nerves; and this, as one or two autopsies appear to show, seems frequently to be by means of the processus cerebelli ad testes. It is certain, at any rate, that optic atrophy occurs not only with tumours of the cerebellum, but with mere wasting diseases of that organ; so that creeping degeneration, and not pressure alone, may be the agent of destruction.

Finally, I think it not unlikely that the curious tendency seen in some states of the nervous centres to sclerotic degeneration in patches may in many cases account for symptomatic nerve-atrophy. It may be that in these states the optic nerves, on account of their vascularity and rich connective tissue, are always among the first portions to suffer, and to suffer independently of the affection of other partsindependently, that is, of any mechanical or physiological connexion, and in virtue only of an affinity in structure.

There are sad gaps, I know only too well, in these reasonings; and gaps there must be until many careful autopsies have been made, and the parts microscopically examined from the present point of view. I am disposed to think, however, that the considerations I have ventured to place before the profession, though in many parts conjectural, are yet not without interest, and not without promise.* Leeds, Jan. 1870.

\section{THE VALUE OF PERINEAL EXTENSION IN FRACTURES OF THE FEMUR.}

Bт FREDERICK CHURCHILL, M.B., \&e., SURGICAL REGISTRAR TO ST. THOHAS'S HOSPITAL, AND SURGEON TO THE WESTMINSTRE GENERAL DISPENSARY.

IT is well known that in many cases of fracture of the shaft of the thigh-bone it is difficult to maintain or to keep up accurate coaptation of the broken ends of the femur, in consequence of the rotation outwards of the upper fragments by mans of the gemelli, obturators, and other external rotators of the thigh, and the tilting upwards by the action of the psoas and iliacus muscles, no longer balanced by the opposing weight of the limb. Extension, too, can best be obtained only indirectly $b y$ means of the perineal band. It becomes a question how far it is judicious to keep up dailyrenewed extension of the limb by this means.

Great difference of opinion appears to exist on this subject, as far as I have been able to judge from the remarks made by the surgeons whoin I hare had the opportunity of consulting on the subject. Some proceed at once to extend the

* I have erased a paragraph refoning to paralysis of accommodation as an occasional 1 esult of acident to the Lerrous centrs. I believe it oceurs;

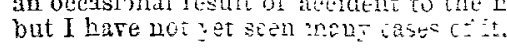

limb and tighten the perineal band whenever they suspect the slightest shortening, and this perhaps repeated daily, with all the force that is necessary to rectify the displacement, until the patient, becoming chafed by the pressure of the splint and bandages, pleads for some less severe treatment. Is not such disturbance of the limb unnecessary, and more likely to aggravate the mischief which it is desired to overcome? The muscles, if undisturbed, will, in a day or two after the injury, return to a quiet, relaxed state, very favourable for promoting the union of the broken bones in good position. Any disturbance is sure to excite violent contraction of the muscles and consequent shortening of the limb. Extension must disturb the processes of union, for the muscles are at once excited to contract, to oppose all attempts at interfering with the steady progress towards consolidation of the broken bones. When the muscles are thus kept at a state of tension any slackening of the bandage must lead to further shortening of the limb. The perineal band is of great service for keeping up the extension which was first applied, and for supporting the splint. Probably the long splint, folded in a sheet passed round the limb, the free edge of which is fastened along the outside of the splint with pins, will keep up a more uniform and equable pressure and extension of the limb. By carefully watching the patient, any loosening of the perineal bandage may be prevented by gathering up the slack, without injuriously disturbing the limb. It is no doubt of great importance to keep up a uniform tension of the perineal band. In fractures of the thigh, with firm perineal extension the patients, especially children, are almost sure to tilt the pelvis and the rest of the body over to that side where they can lie most at their ease, and this must seriously interfere with the accurate coaptation of the broken surfaces. The two following cases occurred in the practice of a friend, who kindly gave me the opportunity of carefully watching the patients throughout, and by whose permission $I$ am now enabled to publish the cases in proof of my statement. In Case 1, notwithstanding the daily and vigorous use of extension, the limb, at first a quarter of an inch shorter, was found to be as much as an inch shorter than the other leg a fortnight after the receipt of the injury, when, the thigh and buttock becoming chafed, extension was discontinued, the perineal band being kept moderately tight. The bone became firmly united, with about a quarter of an inch of shortening, three weeks after.

CASE 1. Fractured femur, treated by firm perineal extension. M. I__, aged nine, was run over by a light spring cart on Jan. 13th, 1869, and the right femur was fractured about the centre of the shaft. The limb was put up and extended upon the long splint, but with a quarter of an inch of shortening. On the 16 th the limb was measured, but there was no shortening. On the 26th there was an inch of shortening, although extension had regularly been applied, and that with considerable force and frequency. On Feb. 1st, extension of the limb was suspended, in consequence of the groin and perineum becoming chafed, but the perineal band was kept firm. She was dismissed, cured, six weeks after, with a quarter of an inch of shortening.

Perineal extension by means of pulleys or weights is in some cases of great service, especially where the fracture is oblique. Case 2 is one where manual extension was applied for some time daily, but without gaining any permanent advantage. A seven-pound weight was applied with rack and pulley, and the bone became firmly united, with half an inch of shortening.

CASE 2. Oblique fracture of femur, treated by firm extension with the long splint and putliey.-E. S-, aged eleven, was knocked down by a cart and run over. When first visited by her medical attendant, she was found to have sustained a fracture of the right femur, about the centre of the shaft. The limb was extended unon a long outside splint and perineal band, and manual extension was had recourse to daily, but without gaining anv permanent advantage, there being still $1 \frac{1}{4}$ in. of shortening. Three weeks after receipt of injury, the limb was put up afresh, and extension made by a pulley fixed at the toot of the bed, with a $7 \mathrm{lb}$. weight attached. She was dismissed with firm union of fracture, and ouly in. of shorteming.

Great George-street, Westminster, Jan. 1870. 